significant improvement in VAS $(\mathrm{p}=, 032)$, sleep scores $(\mathrm{p}=$, $035)$, FIQ item rating fatigue ( $\mathrm{p}=, 002)$, FIQ items rating tension $(\mathrm{p}=, 028)$ and depression $(\mathrm{p}=, 004)$ but not in TP between initial and last visits. When records were analysed case by case, resistant patients were detected and only a few patients were seemed to have a longtime improvement, and some triggering factors such as emotional trauma, minor disease such as flu etc. found to affect patients? symptoms.

Conclusion Diagnosis, assessment and follow-up of patients with fibromyalgia is not easy because of subjective, variable symptoms. Most of the patients seemed to have good times and bad times. Results of the short term outcomes may be good, but most of the patients did not maintain improvement in the longer term, they also needed to change the drug because of loss of efficacy or side effects and other treatment modalities were combined.

\section{SAT0147 CORRELATION BETWEEN FIBROMYALGIA IMPACT QUESTIONNAIRE (FIQ) AND CLINICAL SYMPTOMS IN FIBROMYALGIA}

A Gür, M Karakoç, K Nas, R Çevik, AJ Saraç, F Erdogan. Physical Medicine and Rehabilitation, Dicle University, Diyarbakir, Turkey

\subsection{6/annrheumdis-2001.606}

Background Several well established instruments are available to measure health status and functional disability in persons with rheumatic diseases. Although both instruments are reliable and valid for several rheumatic disease groups, no formal psychometric testing of instruments have been reported for the population with fibromyalgia.

Objectives The study was designed to investigate the correlation between Fibromyalgia Impact Questionnaire (FIQ) and clinical symptoms, Health Assessment Questionnaire (HAQ) in patients with fibromyalgia in Turkey.

Methods FIQ is an assessment and evaluation instrument developed to measure physical functioning, work status, depression, anxiety, sleep, pain, stiffness, fatigue, and well being of fibromyalgia patients. We administered the FIQ and HAQ to 64 patients with fibromiyalgia and 48 healthy persons. Severity of relevant clinical symptoms (pain, fatigue, sleep disturbance, morning stiffness, muscle spasm, number of tender points, sensitivity of trigger points) were assessed.

Results The mean age of the patients and healthy group were $27,98+7,23$ and $28,75+5,67$, respectively $(p>0.05)$. Disease duration was 4,09+3,42 years. Correlation between FIQ and HAQ scores were rho $=0.46(p<0.01)$. Significant correlations were obtained between the FIQ scores and severity of clinical symptoms (morning stiffness $\mathrm{r}=0.42(\mathrm{p}<0.01$ ), fatigue $\mathrm{r}$ $=0.26(\mathrm{p}<0.05)$, pain $\mathrm{r}=0.67(\mathrm{p}<0.01)$, sensitivity $\mathrm{r}=$ $0.25(\mathrm{p}<0.05))$. In addition, significant correlations were obtained between the HAQ scores and number of tender points $r=0.28(p<0.05)$, morning stiffness $r=0.28(p<0.05)$, pain $\mathrm{r}=0.37(\mathrm{p}<0.01)$.

Conclusion In conclusion, the FIQ is a reliable and valid instrument for measuring functional disability in Turkish patients with fibromiyalgia. In addition, our study suggest that FIQ is more significant than HAQ in correlations with clinical symptoms in patients with fibromiyalgia.

\section{SAT0148 FIBROMYALGIA SYNDROME CHARACTERISED BY PATIENT-REPORTED SLEEP, FATIGUE, MOOD AND QUALITY OF LIFE}

${ }^{1} \mathrm{AM}$ Sesti, ${ }^{1} \mathrm{AE}$ Corbin, ${ }^{1} \mathrm{C}$ McLaughlin-Miley, ${ }^{1} \mathrm{M}$ Jaffe, ${ }^{1} \mathrm{~J}$ Moore, ${ }^{1} \mathrm{JP}$ Young, 'L LaMoreaux, ${ }^{1} \mathrm{U}$ Sharma, ${ }^{2} \mathrm{M}$ Versavel. ' Clinical, Pfizer, Ann Arbor, USA; ${ }^{2}$ Clinical, Pfizer, Fresnes, France

\subsection{6/annrheumdis-2001.607}

Background Fibromyalgia (FM) is a chronic condition of pain, tender points and multiple associated symptoms. A diagnosis is made by the ACR 1990 criteria requiring a history of widespread pain and pain in 11 of 18 tender points. Although pain is required for a diagnosis, the associated symptoms contribute to the syndromatic nature of the condition. This trial included measures of sleep, fatigue, mood, QoL and pain.

\section{Objectives}

Methods 529 fibromyalgia patients per ACR criteria were assessed at baseline after discontinuing meds used for FM pain/ insomnia (e.g. antidepressants, sedatives). The questionnaires were the Medical Outcomes Study Sleep Scale (MOS-SS), Multidimensional Assessment of Fatigue (MAF), Hospital Anxiety and Depression Scale (HADS) and SF-36. The MOS-SS has 12-items with an index score and 7 subscales: disturbance, snoring, awakening short of breath/headache (SOB/HA), adequacy, somnolence (range 0-100); quantity of sleep (reported hours); and, optimal sleep (\% with 7-8 h). Higher scores on the MOS-SS indicate more of the measured domain. The MAF has 16 items and 1 global index score from items measuring severity, distress, impact on activities and frequency of fatigue (range 1-50). The HADS has 14-items for anxiety/depression ranging from 0-21. Higher MAF and HADS scores indicate greater impairment. The SF-36 has 8 subscales measuring general health status with higher scores indicating better health states.

Results Demographics and pain scores are reported in the companion abstract by Corbin, et al. 2001. Baseline MOS-SS were: overall problems (62.3), disturbance (62.5), snoring (36.9), SOB/ HA (36.1), adequacy (19.7), somnolence (49.5), quantity (5.6), and $21.7 \%$ reported optimal sleep. The fatigue index was 38.9 and the HADS scores were mild with anxiety (10.1) and depression (8.6). SF-36 scores were physical function (40.5), role physical (15.2), bodily pain (27.6), general health (47.5), vitality (20.4), social functioning (48.8), role-emotional (46.0) and mental health (58.7).

Conclusion These data suggest that FM patients have impaired sleep and concomitant fatigue based on relatively high index scores. The predominant sleep problems were disrupted and inadequate sleep with a fair amount of somnolence. Patients reported low quality of life, particularly on domains of bodily pain, role physical, and vitality. Along with a high level of pain, impairments in sleep, fatigue and QoL were reported in this FM population.

\section{SAT0149 FIBROMYALGIA AND BENIGN JOINT HYPERMOBILITY SYNDROME}

P Borman, D Keskin, H Bodur. Department of Physical Medicine and Rehabilitation, Numune Education and Research Hospital, Ankara, Turkey

10.1136/annrheumdis-2001.608

Background Fibromyalgia syndrome is a chronic rheumatic condition characterised by widespread musculoskeletal pain. 
Objectives The aim of this study was to investigate the relationship between benign joint hypermobility syndrome (BJHS) and FMS.

Methods Thirty-four fibromyalgia patients and 30 healthy control subjects with a mean age of $32.6 \pm 7.8$ and $38.8 \pm 11.1$ years respectively, were recruited to the study. Data about demographical and clinical characteristics of the subjects including age, sex, widespread pain, number of specific tender points and associated symptoms were recorded. The joint hypermobility was evaluated depending on the Beighton score and the diagnosis of BJHS was considered according to the revised criteria for the diagnosis of BJHS (Brighton 1998).

Results There were 2 male and 32 female subjects in each group. The mean number of tender points $(14.7 \pm 1.9$ vs $2.5 \pm 3.1)$, associated symptoms $(7.1 \pm 1.7$ vs $2.5 \pm 1.6)$ and Beighton score $(3.4 \pm 1.3$ vs $1.7 \pm 1.9)$ were significantly higher in the FMS group. The BJHS was present in $2(5.8 \%)$ of FMS and 1 $(2.9 \%)$ of the control subjects.

Conclusion The fibromyalgia patients may be more hypermobile than the control subjects but BJHS is a different clinical entity having no relationship with FMS.

\section{Osteoporosis - Clinical aspects and treatment}

\section{AB0170 THE SIMVASTATIN EFFECT ON OSTEOPOROSIS}

S Sokolovic, F Gavrankapetanovic, V Gerc, A Arslanagic, M Kulic. Department of Rheumatology, University Medical Center, Sarajevo, Bosnia and Herzegovina

\subsection{6/annrheumdis-2001.609}

Background The Osteoporosis has always been a great problem for the clinicians in every country, since this disorder brings higher morbidity, disability and mortality.

The Statins, lipid lowering drugs, have been recently shown to have positive impact on the osteoporosis, i.e. the bone mineral density, where the " $\mathrm{T}$ " score has increased in patients taking these drugs for hiperlipidemia.

Objectives The objective of this research is to investigate the potential efficiency of Simvastatin (Lipex) on BMD score i.e. T score in patients suffering from postmenopausal osteoporosis.

Methods An open randomised Prospective Control Study has been designed.

The patients with the postmenopausal osteoporosis have been selected in one group and they received lipex $10 \mathrm{mg}$ plus 500 Calcium at bed time. The other group of potmenopausal women, served as the control one, was assigned to receive only $500 \mathrm{mg}$ of Calcium at the evening meal. Total number of individuals in each group was thirty three. Laboratory test including the risk factor stratifications were detected on baseline and after 3. The statistical analysis was done between two groups.

Results The results obtained in this study showed the significant improvement in the group of patients receiving lipex and the score is much higher than those taking calcium only.

This BMD result, i.e. T score, has been found to be about $30 \%$ higher in simvastatin group.

The positive effect on lipid profile has been gained as well. The well-being improvement has also been notified.
Conclusion The statins, in our research simvastatin (lipex), has been proven in our study to have a very positive effect on the treatment of osteoporosis.

So, beside the primary effect of statins on lowering cholesterol levels, this is the other option and positivity of this drug.

These medications can be added to the list of therapy in osteoporosis.

\section{AB0171 IMPACT OF DEGENERATIVE RADIOLOGICAL ABNORMALITIES AND VERTEBRAL FRACTURES ON THE EVALUATION OF SPINAL BONE DENSITY IN WOMEN WITH OSTEOPOROSIS}

L Paiva, S Filardi, AM Pinto-Neto, A Samara, JF Marques-Neto. Internal Medicine, State University of Campinas (UNICAMP), Campinas, Brasil

\subsection{6/annrheumdis-2001.610}

Background Osteophytes and lumbar spine fractures can hinder bone density interpretation.

Objectives The objective of this study was to establish the relationship between densitometric measurements and degenerative radiological findings of the lumbar spine, in women with osteoporosis.

Methods The study consisted of ninety-six postmenopausal women presenting osteoporosis in their lumbar spine bone density, DEXA, LUNAR-DPX. Fractures, osteophytes and aortic calcifications were evaluated by simple $\mathrm{X}$-rays of thoracic and lumbar spine.

Results The X-rays confirmed lumbar fractures in $24.7 \%$, osteophytes in $33.3 \%$ and calcifications of the aorta in $30.2 \%$. The mean BMD was $0.783 \mathrm{~g} / \mathrm{cm}^{2}$ and the mean T-score was ?3.47 DP. Neither fractures, nor aortic calcifications had significant influence on $\mathrm{BMD}(\mathrm{p}=0,36$ e $\mathrm{p}=0,09$ respectively) despite the fractured vertebrae having greater BMD $(\mathrm{p}<0,02)$. Patients with lumbar spine osteophytes showed greater BMD $(p=0,04)$. Only osteophytosis was associated to lumbar spine BMD ( $\mathrm{p}=$ $0,008)$.

Conclusion Osteophytes and lumbar spine fractures can hinder bone density interpretation. Based on these findings, the interpretation of densitometric results should be carried out together with that of a simple lumbar spine X-ray.

\section{REFERENCES}

1 Heaney RP, Recker RR, Saville PD. Menopasal changes in bone remodeling. I Lab Clin Med. 1978;92:953-63

2 Kleerekoperm KS. Metabolic bone diseases sec IV primer on the metabolic diseases and disorders of mineral metabolism. 4th edn. Philadephia: Lippincott Williams \& Wilkins, 1999

\section{AB0172 TURNER SYNDROME AND PURE GONADAL DYSGENESIS: A STRONG RISK FACTOR FOR OSTEOPENIA AND OSTEOPOROSIS}

C Benetti-Pinto, AJ Bedone, L Magna, JF Marques-Neto. Internal Medicine, State University of Campinas (UNICAMP), Campinas, Brazil

\subsection{6/annrheumdis-2001.611}

Background During the puberal period, the hormonal production is directly associated to bone mass, and related to the development of the peak of bone mass.

Objectives In order to evaluated the role of Primary Hypoestrogenism as a risk factor for osteopenia, 39 women, aged between 16 and 35 years old, with Pure Gonadal Dysgenesis and Turner 